\title{
The timing of the formation and usage of replicase clusters in S-phase nuclei of human diploid fibroblasts
}

\author{
IAN R. KILL ${ }^{1}$, JOANNA M. BRIDGER ${ }^{1}$, KEITH H. S. CAMPBELL ${ }^{1}$, GABRIELA \\ MALDONADO-CODINA ${ }^{2}$ and CHRISTOPHER J. HUTCHISON ${ }^{1, *}$ \\ ${ }^{1}$ Department of Biological Sciences, The University, Dundee DD1 4HN, Scotland \\ ${ }^{2}$ Department of Biochemistry, The University, Dundee DD1 4HN, Scotland \\ * Author for correspondence
}

\begin{abstract}
Summary
The sites of nascent DNA synthesis were compared with the distribution of the proliferating cell nuclear antigen (PCNA) in S-phase nuclei of human diploid fibroblasts (HDF) by two in vitro techniques. Firstly, proliferating fibroblasts growing in culture that had been synchronised at S-phase were microinjected with the thymidine analogue biotin-11-dUTP. The sites of incorporation of biotin into injected cells were compared with the distribution of PCNA by indirect immunofluorescence microscopy and laser scanning confocal microscopy (LSCM). In common with other studies, a progression of patterns for both biotin incorporation and PCNA localisation was observed. However, we did not always observe coincidence in these patterns, the pattern of biotin incorporation often resembling the expected, preceding distribution of PCNA. In nuclei in which the pattern of biotin incorporation appeared to be identical to the distribution of PCNA, LSCM revealed that not all of the sites of PCNA immunofluorescence
\end{abstract}

were incorporating biotin at the same time. Secondly, nuclei which had been isolated from quiescent cultures of HDF were innoculated into cell-free extracts of Xenopus eggs which support DNA replication in vitro. Following innoculation into these extracts DNA replication was initiated in each nucleus. The sites of DNA synthesis were detected by biotin-11-dUTP incorporation and compared with the distribution of PCNA by indirect immunofluorescence. Only a single pattern of biotin incorporation and PCNA distribution was observed. PCNA accumulated at multiple discrete spots some $15 \mathrm{~min}$ before any biotin incorporation was observed. When biotin incorporation did occur, LSCM revealed almost complete coincidence between the sites of DNA synthesis and the sites at which PCNA was localised.

Key words: replicase clusters, PCNA, fibroblasts.

\section{Introduction}

The proliferating cell nuclear antigen (PCNA) was initially described as a nuclear autoantigen, restricted to proliferating cells, that reacted with autoimmune sera from certain patients with systemic lupus erythematosis (Miyachi et al., 1978). A similar nuclear protein was described by Bravo and Celis (1978) and was named cyclin. Subsequently, it was shown that PCNA and cyclin were identical (Matthews et al. 1984). Immunofluorescence studies have revealed that there are two populations of PCNA: a soluble form that is lost following fixation of cells with organic solvents, and an insoluble form (Bravo and MacDonald-Bravo, 1987). The soluble form displays a diffuse nuclear staining pattern and is detectable throughout the cell cycle. In contrast, the distribution of insoluble PCNA changes in a characteristic way throughout S-phase and closely resembles the pattern of DNA replication detected by 5-bromodeoxyuridine (BrdUrd) incorporation (Bravo, 1986; Bravo and MacDonald-Bravo, 1987; Nakamura et al. 1986). These observations suggested that PCNA was either directly involved in cellular DNA replication or in its control. The subsequent Journal of Cell Science 100, 869-876 (1991)

Printed in Great Britain (C) The Company of Biologists Limited 1991 discovery that PCNA is functionally identical to the auxilliary protein for DNA polymerase delta (Tan et al. 1986; Prelich et al. 1987a; Bravo et al. 1987) and is required for leading strand synthesis in simian virus 40 (SV40) DNA replication in vitro (Prelich et al. 1987b; Prelich and Stillman, 1988) implied a role in the elongation phase of DNA replication. More recently, experiments in which anti-sense oligonucleotides or microinjected antibodies were used to functionally deplete PCNA from cells in cultures, implied that it is essential for cellular DNA replication (Wong et al. 1987; Jaskulski et al. 1988; Zuber et al. 1989). The existence of two forms of PCNA (Bravo and MacDonald-Bravo, 1987) led these authors to conclude that the soluble form is not involved in DNA replication and that the insoluble form is associated with the sites of on-going DNA synthesis. This hypothesis is supported by a recent report, which shows that a greater fraction of PCNA is insoluble due to chromatin association during S-phase than at any other stage of the cell cycle (Morris and Matthews, 1989).

Despite these reports, the evidence for the association of PCNA with nuclear replication complexes has been circumstancial. Since detection of BrdUrd incorporation 
requires the pre-treatment of cells with $\mathrm{HCl}$, this precludes double indirect immunofluorescence microscopy. More recently, however, biotinylated nucleotide triphosphates have been used to study the patterns of DNA replication in S-phase nuclei (Blow and Watson, 1987; Nakayasu and Berezney, 1989). In cell-free extracts of Xenopus eggs that assemble nuclei and initiate semiconservative DNA replication in vitro, biotin-11-dUTP incorporation occurs at multiple discrete sites throughout S-phase nuclei (Mills et al. 1989). Unlike BrdUrd, biotin11-dUTP cannot cross the plasma membrane. However, in permeabilised kangeroo kidney PtK-1 cells and mouse 3T3 fibroblasts, biotin-11-dUTP is incorporated into replication granules that are similar to the pattern of BrdUrd incorporation in vitro (Nakayasu and Berezney, 1989) and resemble previously reported localisations of PCNA and DNA polymerase alpha (Bravo and MacDonald-Bravo, 1987; Nakamura et al. 1986). Thus, biotinylated nucleotides appear to provide a means of comparing directly the sites of DNA replication with the distribution of proteins thought to be involved in the replication complex. To this end we have used double indirect immunofluorescence to compare the timing of the appearance of PCNA foci within replicon clusters and their relative distributions within S-phase nuclei, by microinjection of biotin-11-dUTP into tissue culture cells and by labelling cell-free extracts of Xenopus eggs with biotin-11-dUTP. Our results show that PCNA accumulates at the sites of DNA replication some time before any DNA synthesis can be detected at those sites. This implies that PCNA is organised into a preinitiation complex that is modified before use.

\section{Materials and methods}

\section{Cell culture and synchronisation}

Adult HDF (strain 1BR.3, passage 6-10) were obtained from a punch biopsy (Arlett et al. 1975). The cells were grown in Dulbecco's modified Eagle's medium (DMEM) supplemented with $10 \%(\mathrm{v} / \mathrm{v})$ newborn calf serum (NCS) and antibiotics (10 units ml ${ }^{-1}$ of penicillin, $50 \mu \mathrm{g} \mathrm{ml}^{-1}$ of streptomycin) at a seeding density of $3 \times 10^{3}$ cells cm $\mathrm{cm}^{-2}$ in $90 \mathrm{~mm}$ culture dishes. For immunofluorescence and microinjection studies, cells were plated onto $13 \mathrm{~mm}$ diameter glass coverslips at a density of $3 \times 10^{3}$ cells $\mathrm{cm}^{-2}$ and allowed to grow for two days. Cells were synchronised at the $G_{1} / S$ boundary in the following way: cells on coverslips were washed twice with serum-free DMEM and refed with DMEM containing $0.5 \%$ NCS. After 7 days, cultures were refed with DMEM containing $10 \%$ NCS. After $8 \mathrm{~h}$, the medium was supplemented with $1 \mathrm{~mm}$ hydroxyurea (HU) and incubated for a further $10 \mathrm{~h}$. Arrested cells were allowed to progress through the cell cycle by washing twice and refeeding with DMEM containing $10 \%$ NCS. Cells on coverslips were prepared for immunofluorescence staining by washing twice with phosphate-buffered saline (PBS) and fixing with methanol/acetone $(1: 1, \mathrm{v} / \mathrm{v})$ for $4 \mathrm{~min}$ at $4^{\circ} \mathrm{C}$.

\section{Isolation of somatic nuclei from quiescent $H D F$}

HDF were subcultured into $90 \mathrm{~mm}$ dishes $\left(3 \times 10^{3}\right.$ cells $\left.\mathrm{cm}^{-2}\right)$ in medium containing $10 \%$ NCS. After $48 \mathrm{~h}$ the cells were washed with serum-free medium and refed with DMEM containing $0.5 \%$ NCS. After 7 days the cells were washed three times with PBS at $4^{\circ} \mathrm{C}$ and then twice with nuclear isolation buffer (NIB) $(10 \mathrm{~mm}$ Tris-HCl, $10 \mathrm{~mm} \mathrm{NaCl}, 3 \mathrm{mM} \mathrm{MgCl}_{2}, 0.5 \%$ (v/v) NP40, pH 7.6) at $4^{\circ} \mathrm{C}$. The cells were collected by scraping into $1 \mathrm{ml}$ NIB with a rubber policeman and transferred to a pre-cooled $1 \mathrm{ml}$ Dounce homogeniser. The cells were ruptured by gentle homogenisation with a tight fitting pestle and the release of nuclei was monitored by phase contrast microscopy. The suspension was diluted to $10 \mathrm{ml}$ and gently layered over a $4 \mathrm{ml}$ sucrose cushion $(30 \% \mathrm{w} / \mathrm{v}$ in
NIB). Nuclei were recovered by centrifugation at $2400 \mathrm{revs} \mathrm{min}^{-1}$ for $10 \mathrm{~min}$ in an MSE Centaur 2 benchtop centrifuge. Isolated nuclei were resuspended in $10 \mu \mathrm{l}$ of SUNaSp (Gurdon, 1976) and counted.

\section{Microinjection of biotin-11-dUTP}

HDF grown on coverslips, and that had been sychronised at S-phase, were transferred to $35 \mathrm{~mm}$ culture dishes (1 coverslip/ dish) containing $10 \%$ NCS. Biotin-11-dUTP (400 $\mu \mathrm{m}$ in SUNaSp) was injected into the nuclei of $200-500$ cells at the centre of each coverslip, using an Eppendorf semi-automatic microinjection system. In order to obtain cells at all stages of S-phase, injections were carried out from $3-10 \mathrm{~h}$ after release from HU. Immediately after injection, the coverslips were transferred to fresh medium and incubation continued for $90 \mathrm{~min}$. For indirect immunofluorescence, cells were fixed, washed in PBS stained and mounted.

\section{Preparation of egg extract}

Extracts were prepared from unfertilised Xenopus eggs according to the method of Hutchison et al. (1988). Briefly, eggs were collected from mature female frogs after a single injection of 700 i.u. human chorionic gonadotrophin (Intervet, U.K.) into the dorsal lymph sac $16 \mathrm{~h}$ before use. After dejellying, the eggs were rinsed three times in saline tap water $(110 \mathrm{~mm} \mathrm{NaCl})$, twice in distilled water and twice in ice-cold extraction buffer $(20 \mathrm{~mm}$ Hepes, pH 7.5, $100 \mathrm{mM} \mathrm{KCl}, 5 \mathrm{~mm} \quad \mathrm{MgCl}_{2}, 2 \mathrm{mM}$ 2-mercaptoethanol). The eggs were packed into $5 \mathrm{ml}$ Beckman centrifuge tubes and excess buffer was removed before centrifugation at $10000 \mathrm{~g}$ for $10 \mathrm{~min}$. The soluble extract was removed and treated with $50 \mu \mathrm{g} \mathrm{ml}^{-1}$ cytochalasin B before centrifugation a second time at $10000 \mathrm{~g}$ for $10 \mathrm{~min}$. The final extract was made 80 kallikrein units $\mathrm{ml}^{-1}$ with aprotonin and $10 \%(\mathrm{v} / \mathrm{v})$ with glycerol Extracts were frozen by dropping $40 \mu \mathrm{l}$ alıquots into liquid nitrogen.

\section{Biotin-11-dUTP labelling in vitro}

Egg extracts were thawed rapidly, placed on ice and supplemented with $60 \mathrm{~mm}$ phosphocreatine, $150 \mu \mathrm{g} \mathrm{ml}^{-1}$ creatine phosphokinase. Isolated somatic nuclei were added at $10^{5} / 100 \mu$ extract and incubated at $21^{\circ} \mathrm{C}$. At $30 \mathrm{~min}$ intervals, biotin-11dUTP was added to $10 \mu \mathrm{l}$ aliquots of the extract to a final concentration of $4 \mu \mathrm{M}$. Incubations were continued for $30 \mathrm{~min}$ before reactions were terminated by adding $200 \mu \mathrm{l}$ of EGS (1 mM ethylene glycol bis-succinic acid $N$-hydroxysuccinimide ester) and incubating for $30 \mathrm{~min}$ at $37^{\circ} \mathrm{C}$. The nuclei were recovered by

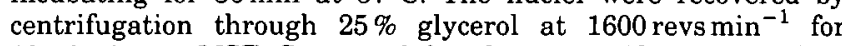
$10 \mathrm{~min}$ in an MSE Centaur 2 benchtop centrifuge, onto glass coverslips.

\section{Indirect immunofluorescence microscopy}

Coverslips containing fixed cells or nuclei were washed with PBS, covered with $10 \mu \mathrm{l}$ of anti-PCNA antibody (1:10 in PBS containing $1 \% \operatorname{NCS}(\mathrm{v} / \mathrm{v})$; Alpha Labs) and incubated overnight at $4^{\circ} \mathrm{C}$ in a humidified atmosphere, then washed three times with PBS. For double indirect immunofluorescence, coverslips were covered with $10 \mu \mathrm{l}$ of the following solution: FITC-rabbit anti-human IgG, final dilution 1:25 (v/v) in PBS/NCS (Jackson Immuno Research) and Texas red-streptavidin, final dilution $1: 100(v / v)$ in PBS/NCS (Amersham). After incubation for $4 \mathrm{~h}$ at $4^{\circ} \mathrm{C}$ in a humidified atmosphere, the coverslips were washed three times in PBS, once in distilled water, mounted on glass slides in $50 \%(\mathrm{v} / \mathrm{v})$ glycerol in PBS containing $1 \mu \mathrm{g} \mathrm{ml}^{-1} 4,6$-diamidino-2-phenylindole (DAPI) isopropyl gallate and sealed with nail varnish. Slides were viewed with a Zeiss Axioskop microscope fitted with a $100 \times$ oil immersion objective, or with a BioRad MRC 600 laser scanning confocal microscope.

\section{Results}

Changes in the nuclear distribution of PCNA during $S$-phase in cultured human diploid fibroblasts

The aim of this study was to examine the distribution of 


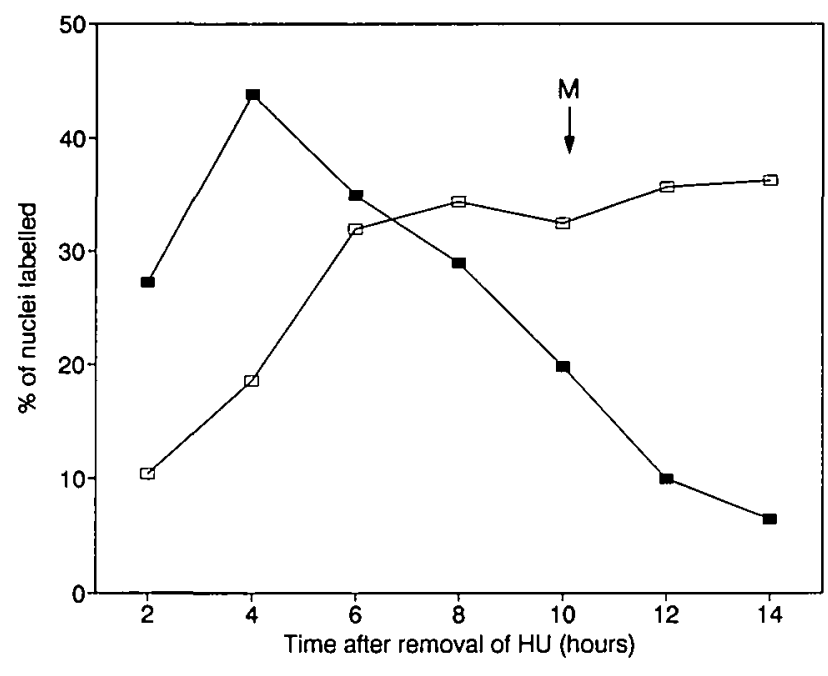

Fig. 1. Changes in the fraction of PCNA-positive cells in cultures of HDF that have been synchronised at S-phase. Cultures of HDF were synchronised at S-phase with HU as described above. After $10 \mathrm{~h}$, HU was removed from some cultures and cells were prepared for indirect immunofluorescence microscopy at $2 \mathrm{~h}$ intervals following release. At the same times, cells were also prepared for immunofluorescence microscopy from cultures which were grown in the continued presence of HU. The graph shows the percentage of cells showing nuclear staining with anti-PCNA antibodies at each time interval. Filled squares represent the fraction of PCNA-positive nuclei in cells released from an HU block. Open squares represent the fraction of PCNA-positive nuclei in cells grown in the continuous presence of $\mathrm{HU}$. M indicates the time at which mitotic figures were first observed. Percentage values were obtained from scores of at least 500 cells.

both PCNA and the sites of DNA replication in individual nuclei. Previous reports have shown that during S-phase, characteristic redistributions of PCNA occur and that similar if not identical patterns are observed for the sites of DNA replication. Therefore, we first examined the accumulation and distribution of PCNA during S-phase in synchronised populations of HDF in culture. Briefly, quiescent cells were stimulated with $10 \%$ NCS and after $8 \mathrm{~h} 1 \mathrm{~mm} \mathrm{HU}$ was added and incubation continued for $10 \mathrm{~h}$. Following removal of $\mathrm{HU}$, cells on coverslips were fixed at $2 \mathrm{~h}$ intervals and stained with anti-PCNA antibodies and with DAPI. Fig. 1 shows the results of one such experiment. In the continuous presence of $\mathrm{HU}$, the percentage of PCNA positive cells increased steadily, reaching a maximum level $24 \mathrm{~h}$ after the addition of the drug. No mitotic cells were observed throughout the duration of the experiment. In parallel cultures, following removal of $\mathrm{HU}$, the percentage of PCNA positive cells reached a maximum level $4 \mathrm{~h}$ later. In these cultures, mitotic cells were first observed $10 \mathrm{~h}$ after removal of $\mathrm{HU}$.

In previous reports the distribution of PCNA has been correlated with the period of S-phase (Bravo and MacDonald-Bravo, 1987). In our experiments, the patterns of PCNA staining in individual nuclei were classified into one of four types termed A-D (Fig. 2). In type A, very few foci of PCNA staining were observed; in type $B$, a regular granular pattern was observed over the whole of the nucleus; in type $\mathrm{C}$, the staining was again punctated but with more significant fluorescence over the perinuclear region; and in type $\mathrm{D}$, fluorescence was observed in a smaller number of large brightly staining granules.
Fig. 2E shows the frequency of each staining pattern at times following release from the HU block. Both the localisation and temporal redistribution of PCNA resembled previously reported patterns: A corresponding to (a), B to (c/d), C to (e) and D to (f), where letters in parenthesis are from the nomenclature of Bravo and MacDonald-Bravo (1987). We can only deduce that each pattern is representative of a particular part of S-phase from the timing of the peak values. For example, type $B$ is present throughout the experiment but peak values occur at $4 \mathrm{~h}$ post-release, type $\mathrm{C}$ at $8 \mathrm{~h}$ and type $\mathrm{D}$ between 10 and $14 \mathrm{~h}$ (Fig. 2B). However, given this, our results suggest that type $B$ patterns occur in early S-phase; type C during mid to late S-phase and type D in late S-phase. Type A patterns are thought to represent an early stage in the accumulation of PCNA. In contrast to the redistributions of PCNA during progression through S-phase, cells incubated in the continuous presence of $\mathrm{HU}$ arrested with a common type B pattern of staining (data not shown).

\section{DNA synthesis occurs at the sites of PCNA localisation}

In order to compare the distribution of insoluble PCNA and the sites of nascent DNA synthesis in the same cells, we microinjected biotin-11-dUTP into the nuclei of HDF grown on coverslips. Three distinct patterns of biotin-11dUTP incorporation were observed and termed I-III (Fig. 3A-C). These were similar if not identical to those patterns previously reported for the sites of DNA replication in whole and permeabilised cells (Bravo and MacDonald-Bravo, 1987; Nakayasu and Berezney, 1989), and also to the patterns B-D of PCNA distribution described above (Fig. 2).

When the distribution of PCNA and biotin-11-dUTP incorporation was compared in the same cells, a series of combinations of staining patterns were observed. These were divided into two groups: (i) those nuclei showing apparently identical/coincident distributions, i.e. B/I, C/II and D/III (Fig. 4, panels A, B and C); and (ii) those in which the patterns were non-coincident, i.e. C/I, D/II and nuclei of pattern III in which no PCNA staining was observed (Fig. 4, panels D, E and F). Although it appeared that the patterns of biotin-11-dUTP incorporation (I-III) occurred in the same temporal sequence as the patterns (B-D) of PCNA localisation (i.e. type I occuring in early S-phase; type II in mid to late S-phase and type III in late S-phase) in nuclei in which non-coincident staining was observed, the pattern of biotin-11-dUTP incorporation always resembled the expected preceding pattern of PCNA distribution. No DNA replication was detected in nuclei of PCNA pattern A. The detection of non-coincident staining patterns of the type described above is explicable if PCNA relocates to new sites of DNA replication some time before replication occurs at those sites. Thus the pattern of biotin incorporation represents synthesis that has occurred during the previous 90 min while the distribution of PCNA represents synthesis that is about to occur. As cellsynchrony experiments have revealed when different patterns of DNA replication occur during S-phase, we would predict that non-coincident patterns of staining should be more cammon at certain times within a synchronously dividing culture. For example, from Fig. 2 there appears to be a transition from PCNA patterns of type $B$ to patterns of type $C$, while at $4 \mathrm{~h}$ patterns of type $B$ represent between $80 \%$ and $90 \%$ of a culture. In keeping with this, cultures that are injected at $2 \mathrm{~h}$ after release from $\mathrm{HU}$ and fixed at $3.5 \mathrm{~h}$ have only $16.3 \%$ non-coincident 

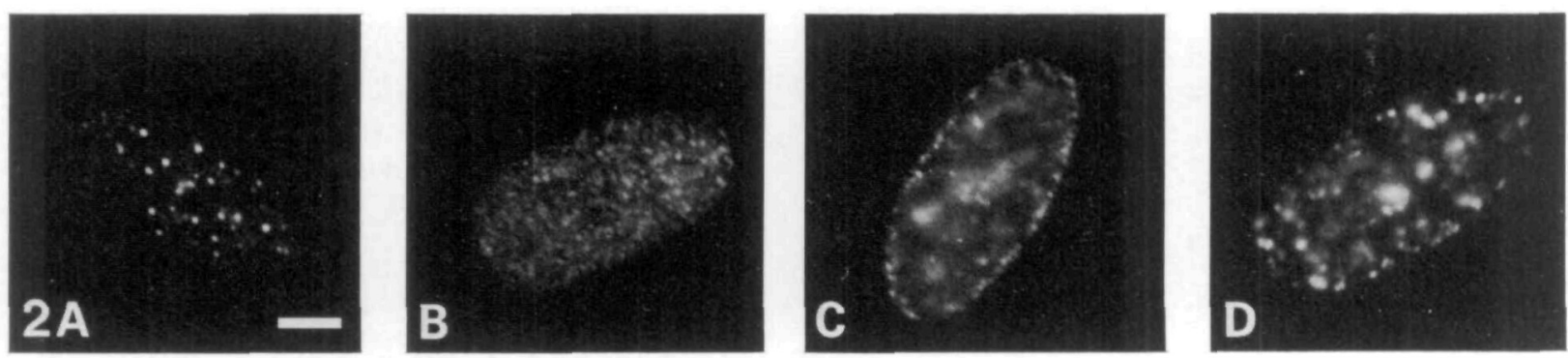

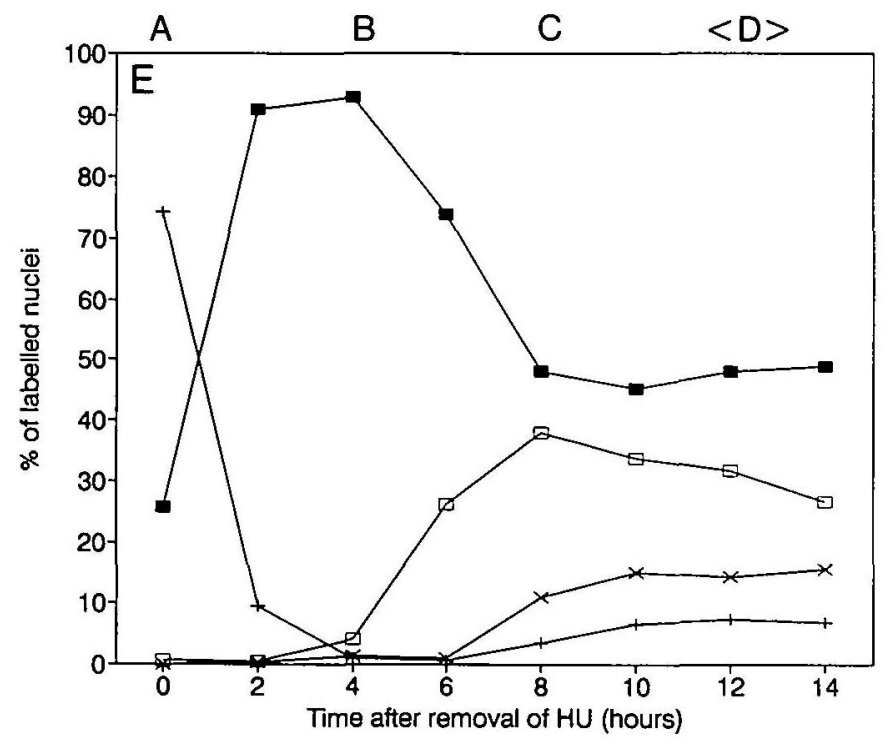

staining. In contrast, cultures injected at $6 \mathrm{~h}$ and fixed at $7.5 \mathrm{~h}$ display $49.2 \%$ non-coincidence.

To analyse further the nuclei of group (i) in which PCNA and biotin-11-dUTP appeared to co-localise, samples representative of each class (i.e. $\mathrm{B} / \mathrm{I}, \mathrm{C} / \mathrm{II}$ and $\mathrm{D} / \mathrm{III}$ ) were examined by LSCM. By optical reconstruction, we were able to superimpose directly the anti-PCNA fluorescence and anti-biotin fluorescence in any confocal plane onto a single image. Fig. 5 shows a series of such reconstructions; in each one the distribution of PCNA appears in green and biotin-11-dUTP incorporation in red. When the two images are superimposed, coincident spots appear yellow. Nuclei of class B/I were of two types occurring at equal frequency: those in which there was complete coincidence between biotin-11-dUTP incorporation and PCNA fluor-
Fig. 2. Changes in the nuclear distribution of PCNA following release from HU. Cultures of HDF were synchronised at S-phase with $\mathrm{HU}$ as described above. Following removal of $\mathrm{HU}$, cells were prepared for indirect immunofluorescence microscopy using anti-PCNA antibodies and examined using a $100 \times$ oil ımmersion Neofluor lens fitted to a Zeiss Axioskop. Panels A-D illustrate the four different patterns of staining that were observed, described as having few foci (A), a regular granular pattern (B), a predominant perinuclear pattern (C) and staining of a few large granules (D). Panel E illustrates the frequency of each type of pattern expressed as a percentage of the total population of PCNA-positive cells at different $(2 \mathrm{~h})$ time intervals following removal of $\mathrm{HU} . \mathrm{A}, \mathrm{B}, \mathrm{C}$ and $\langle\mathrm{D}\rangle$ in $2 \mathrm{E}$ are the times at which the maximum values of each pattern were recorded. Scale bar, $5 \mu \mathrm{m}$.

escence (Fig. 5A) and those in which there was incomplete coincidence (Fig. 5B). In merged images of the latter type, three classes of spot were observed: red spots indicating biotin-11-dUTP incorporation but no corresponding PCNA, green spots indicating PCNA but no corresponding biotin-11-dUTP incorporation, and yellow spots indicating on-going biotin-11-dUTP incorporation at the sites of PCNA accumulation (Fig. 5B). In nuclei of both classes $\mathrm{C} / \mathrm{II}$ and D/III, several examples of incomplete coincidence were also observed. However, on the whole this was less common (Fig. 5C-D).

One interpretation of these data is that PCNA accumulates at the sites of DNA replication as part of a preinitiation complex, some time before DNA synthesis starts. Thus in some nuclei, it is possible to detect PCNA
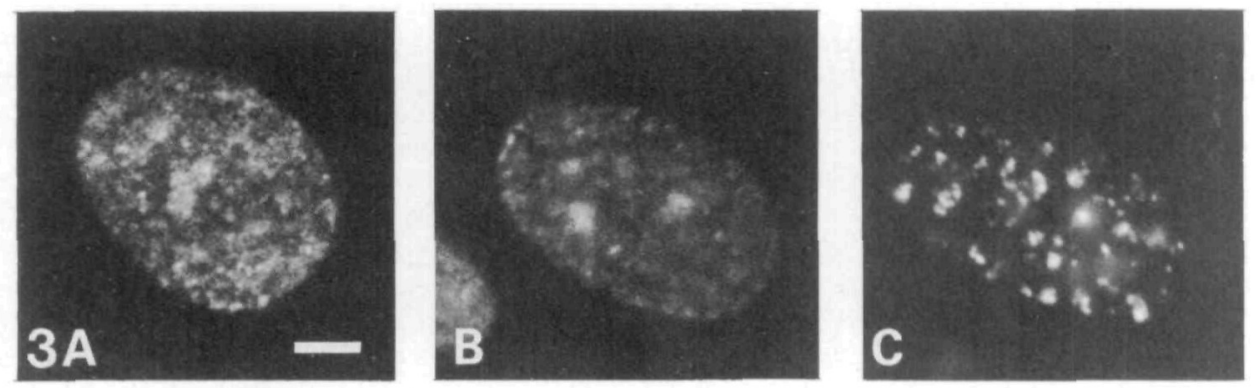

Fig. 3. Changes in the patterns of incorporation of biotin-11-dUTP in nuclei of cells that had been synchronised at S-phase. Cultures of HDF that had been synchronised at S-phase were microinjected with biotin-11-dUTP at $2 \mathrm{~h}$ intervals following release from HU. Cells were prepared for fluorescence microscopy by staining with Texas red-streptavidin. Panels A-C illustrate the three patterns of incorporation which were observed. (A) shows a nucleus in which incorporation has occurred with a regular granular pattern (I), (B) shows a nucleus showing a predominantly perinuclear pattern (II) and (C) shows a nucleus with incorporation in a few large granules (III). Scale bar, $5 \mu \mathrm{m}$. 
PCNA
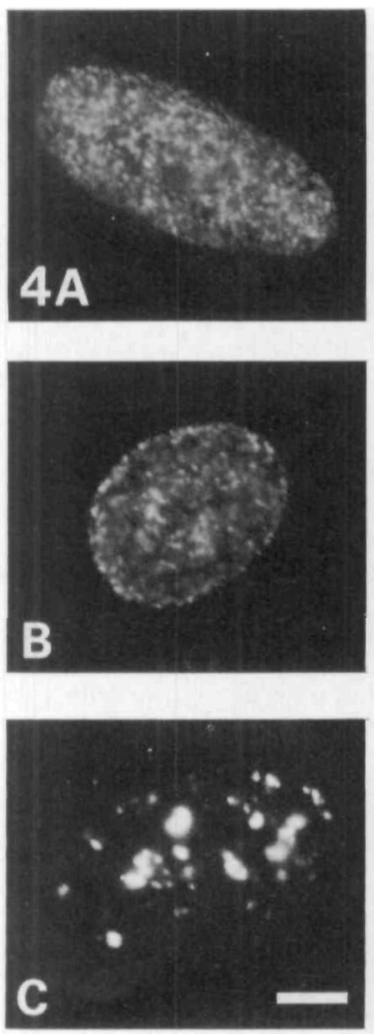

Biotin
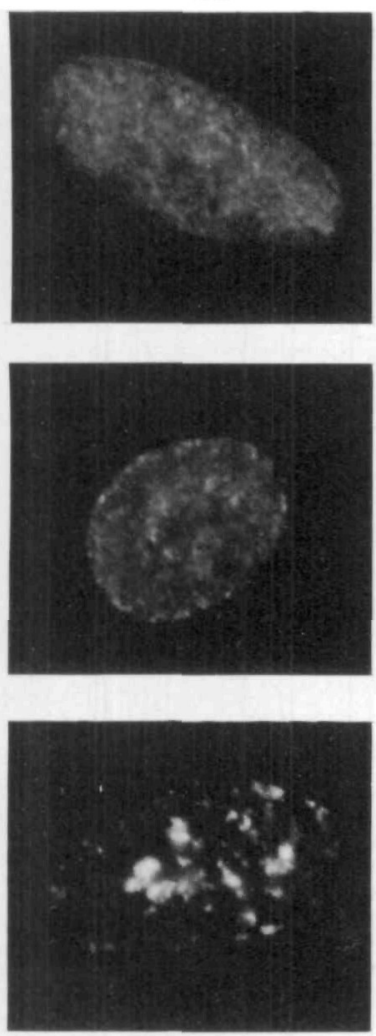

PCNA
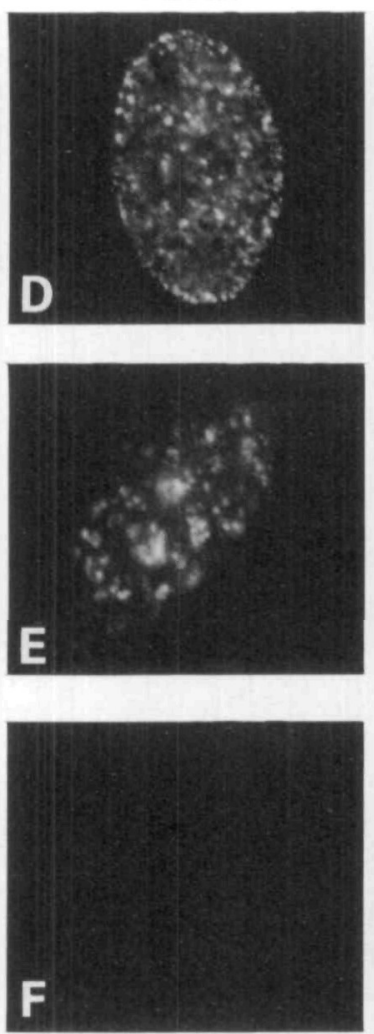

Biotin
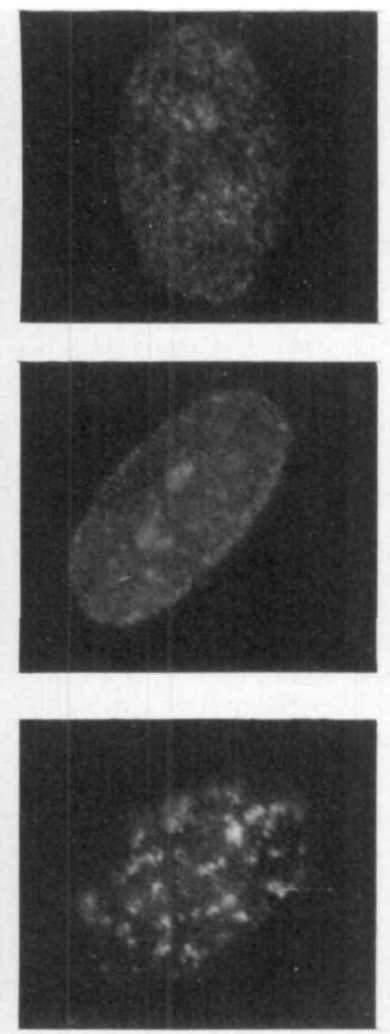

Fig. 4. Coincidence of biotin-11-dUTP incorporation with the distribution of PCNA in microinjected cells. Cells that had been microinjected with biotin-11-dUTP were prepared for fluorescence microscopy by co-staining them with Texas red-streptavidin and anti-PCNA antibodies followed by FITC-rabbit anti-human Ig. Labelled cells were examined using a $100 \times$ oil immersion PlanNeofluor lens fitted to a Zeiss Axioskop UV microscope. Panels A-C illustrate nuclei in which the pattern of biotin-11-dUTP incorporation appeared to be identical to the distribution of PCNA. (A) illustrates a type I/B pattern, (B) a type II/C pattern and (C) a type III/D pattern. Panels (D-F) illustrate nuclei in which the pattern of biotin-11-dUTP incorporation was clearly different from the distribution of PCNA. Panel D illustrates a nucleus in which the distribution of PCNA is predominantly perinuclear but biotin incorporation is in a regular granular pattern (type I/C). Panel E illustrates a nucleus in which the distribution of PCNA is in a small number of large granules but biotin incorporation is predominantly perinuclear (type II/D). Panel F illustrates a nucleus in which there was no PCNA-staining but biotin-11-dUTP incorporation had occurred at a small number of large granules. No other combinations were observed in three separate experiments. Scale bar, $5 \mu \mathrm{m}$.

reorganisation before any biotin-11-dUTP incorporation has occurred at the new sites (see Fig. 4). Furthermore, when DNA synthesis does occur, each 'cluster of replicases' starts independently rather than in synchrony with neighbouring 'clusters'. Since marking injected cells with conventional dyes such as fluorescein-labelled dextrans would not allow us to perform double-fiuorescence microscopy, it was not possible to test this hypothesis by microinjection experiments. However, cell-free extracts of Xenopus eggs that support DNA replication in vitro provide an experimental system in which the stages of assembly and usage of 'clusters of replicases' can be observed. Thus, we have examined the replication of somatic nuclei in such cell-free extracts.

\section{Localisation of PCNA precedes the initiation of DNA replication}

Nuclei were isolated from quiescent cultures of HDF by homogenisation and inoculated into Xenopus egg extracts at a concentration of $10^{5}$ per $100 \mu \mathrm{l}$ of extract. $10 \mu \mathrm{l}$ aliquots were incubated at $21^{\circ} \mathrm{C}$ and pulse labelled with biotin-11dUTP at $30 \mathrm{~min}$ intervals. $30 \mathrm{~min}$ after the addition of biotin-11-dUTP each aliquot was fixed and prepared for fluorescence microscopy. The results of one such experiment are illustrated in Fig. 6. Immunofluorescence microscopy indicated only a single pattern of both PCNA staining and biotin-11-dUTP incorporation that resembled the type B/I pattern seen in fibroblast cultures. Typically, nuclei having an intense spotty distribution of PCNA staining but no biotin-11-dUTP incorporation accumulated some thirty minutes before any DNA synthesis was detected (Fig. 6A,B and E). As this period was identical to the labelling time, a trivial explanation of this result is that PCNA-positive, biotin-negative nuclei represent those in which insufficient biotin had accumulated to be detectable. To exclude this possibility, we pulse- labelled nuclei that were just entering S-phase for 5 min periods at $5 \mathrm{~min}$ intervals. Our results indicate that, while nuclei with a spotty distribution of PCNA represent $25 \%$ of those incubated in an extract for $2 \mathrm{~h}$, PCNA-positive, biotinpositive nuclei do not reach this frequency until $15 \mathrm{~min}$ later (Fig. 6F). This implies that there is a delay of $15 \mathrm{~min}$ between the time at which some replication proteins are assembled at a particular site and the time at which they are actively involved in DNA synthesis.

When DNA synthesis did occur, the pattern of biotin-11dUTP incorporation was indistinguishable from the 
pattern of PCNA staining (Fig. 6C, D and E). Following LSCM and subsequent optical reconstruction of replicating nuclei, it was revealed that $>95 \%$ of the 'replicase clusters' were incorporating biotin-11-dUTP at any one time, implying that initiation was more synchronous in these nuclei (Fig. 7)

\section{Discussion}

\section{Is PCNA part of a pre-initiation complex?}

Previous reports have indicated that PCNA is required for eukaryotic DNA replication and have suggested that active DNA synthesis occurs at the sites of PCNA localisation (Wong et al. 1987; Jaskulski et al. 1988; Zuber et al. 1989; Bravo and MacDonald-Bravo, 1987). However, due to technical limitations there has been no direct evidence that DNA replication occurs at the sites of PCNA localisation. In this study we have used biotin-11-dUTP to compare the sites of DNA replication and PCNA localisation in the same nucleus. Our results demonstrate that although PCNA is located at the sites of active DNA synthesis, it appears to accumulate at these sites in a preinitiation complex up to fifteen minutes before replication starts.

Taking viral DNA replication as a paradigm for chromosomal replication, recent studies have clearly defined the sequential accumulation of replication proteins into stage-specific complexes. For example, SV40 DNA replication in vitro involves first the formation of a 'pre-synthesis' complex involving $\mathrm{T}$ antigen and $\mathrm{SS} 1$, that is then modified by the addition of RF-A to form an unwinding complex and only then by DNA polymerases to form an initiation complex (Fairman and Stillman, 1988; Fairman et al. 1988). PCNA appears to be involved at a fairly late stage and is not part of the pre-synthesis complex, but is required both for elongation and for coordinating leading and lagging strand synthesis (Prelich and Stillman, 1988).

Following Herpes simplex virus infection of CV-1 cells, the centres of host cell replication are reorganised to a smaller number of sites. This reorganisation is coordinated by the virally encoded protein ICP8 (Quinlan et al. 1984), which binds to both viral DNA and the nuclear matrix (Quinlan and Knipe, 1983; Lee and Knipe, 1983). When viral replication is inhibited with sodium phosphonoacetate, reorganisation of host cell proteins to 'prereplicative' complexes still occurs (Quinlan et al. 1984; Wilcock and Lane, 1991). PCNA becomes localised within at least some of these complexes (Wilcock and Lane, 1991).

In both SV40 in vitro replication assays and during HSV infection of CV-1 cells, pre-synthesis or pre-initiation complexes can only be detected if elongation is inhibited (Prelich and Stillman, 1988; Quinlan et al. 1984), indicating that it is a very transitory event that may not involve PCNA. Our data indicate that PCNA appears at the sites of DNA replication up to fifteen minutes before replication begins. Previous studies have shown that in nuclei assembled in Xenopus cell-free extracts, foci of antiPCNA immunofluorescence always co-localise with foci of anti-DNA polymerase alpha immunofluorescence (Hutchison and Kill, 1989). This would imply that both proteins are assembled into a pre-initiation complex. Clearly, replication in Xenopus embryos is much more rapid than in cell-free extracts of Xenopus eggs (Graham and Morgan, 1966; Blow and Watson, 1987), thus the pre-initiation stage of replicase assembly may be artificially lengthened.
Fig. 5. Laser scanning confocal microscope analysis of nuclei co-stained for biotin-11-dUTP incorporation and PCNA. Nuclei that had been co-stained for biotin incorporation and PCNA distribution were examined at a single confocal plane with an MRC-600 Biorad LSCM attached to a Nikon Axiophot fitted with a $63 \times$ oil immersion plan-achromat lens. For these analyses, the variable pinhole aperture was adjusted to its minimum diameter. Optical reconstruction was performed on images obtained from averaged values following 50 scans using a Kalman programme. Anti-PCNA immunofluorescence was observed on channel one (green) and streptavidin fluorescence was observed on channel two (red). In each image, background fluorescence was removed to a base of 30 . In merged images, PCNA fluorescence alone appears green, streptavidin fluorescence alone appears red and areas of coincident fluorescence yellow. Panels A and B illustrate opitical reconstructions of nuclei of type $\mathrm{I} / \mathrm{B}$. Panel $\mathrm{C}$ illustrates an optical reconstruction of a nucleus of type II/C and panel D illustrates an optical reconstruction of a nucleus of type III/D. Scale bar, $5 \mu \mathrm{m}$.

Fig. 7. Laser scanning confocal microscopy of biotin-11-dUTPlabelled nuclei isolated from cell-free extracts of Xenopus eggs. Nuclei which had been labelled with biotin-11-dUTP following incubation in egg extracts were prepared for fluorescence microscopy as described above. Labelled nuclei were observed with an MRC-600 Biorad LSCM attached to a Nikon Axiophot fitted with a $63 \times$ Neofluor lens. Optıcal reconstruction was performed on averaged images obtained following 50 scans using a Kalman programme. PCNA fluorescence was observed on the green channel, biotin/streptavidin fluorescence was observed on the red channel. In merged images co-incident fluorescence appears yellow while non-concident images appear either green (PCNA alone) or red (biotin alone). Scale bar, $5 \mu \mathrm{m}$

However, co-ordination of initiation events during chromosomal replication is presumably more complex than in viral replication. Initiation occurs at multiple sites on each chromosome and these sites appear to be clustered into groups of 300-1000 replication forks (Mills et al. 1989). This organisational complexity may constrain the way in which initiation occurs. In SV40, a single origin of replication is used (Stillman and Glutzman, 1985) and replication can occur bidirectionally from that origin immediately following the formation of a replication bubble by $\mathrm{T}$ antigen and associated host proteins (see Fairman et al. 1988). During chromosomal DNA replication, the additional constraints of assembling replicases at fixed sites within the nucleus (Jackson and Cook, 1986; Bravo and MacDonald-Bravo, 1987; Nakayasu and Berezney, 1989) and of clustering replicases into groups of 1000 , may dictate that all of the proteins required for both the initiation and elongation phases are assembled before initiation can proceed.

The timing of the use of individual 'replicase clusters' appears to differ in cells grown in culture compared with isolated nuclei in cell-free extracts. In culture, each focus of anti-PCNA immunofluorescence incorporates biotin-11dUTP independently of its neighbour. In contrast, when nuclei replicate in cell-free extracts, incorporation of biotin-11-dUTP appears to start synchronously at all PCNA sites in any one nucleus. This apparent difference may be artificial and could reflect the much shorter time that a nucleus spends in S-phase in egg extracts. S-phase takes up to $10 \mathrm{~h}$ to complete in HDF, thus discrete phases during replication, such as asynchrony in initiation, are easy to detect. In contrast, our pulse-labelling studies indicate that isolated nuclei replicate over a period of $90 \mathrm{~min}$ in egg extracts. Thus, asynchrony in initiation 
PCNA

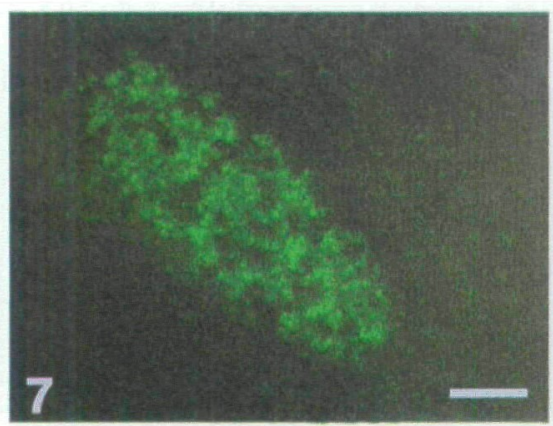

PCNA
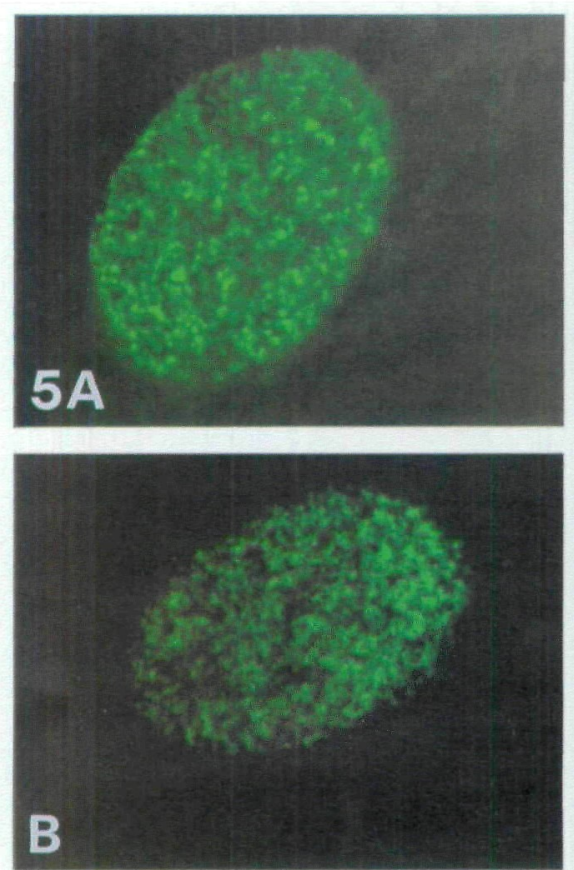

C

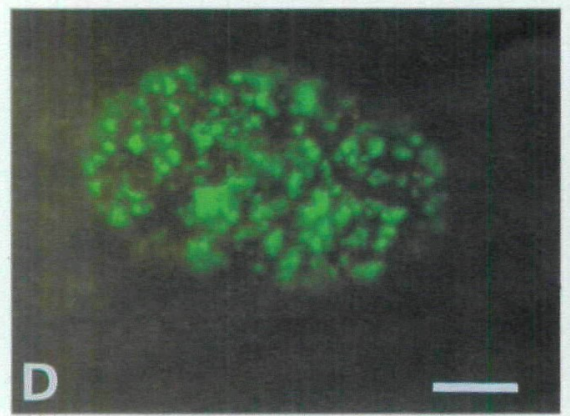

Biotin

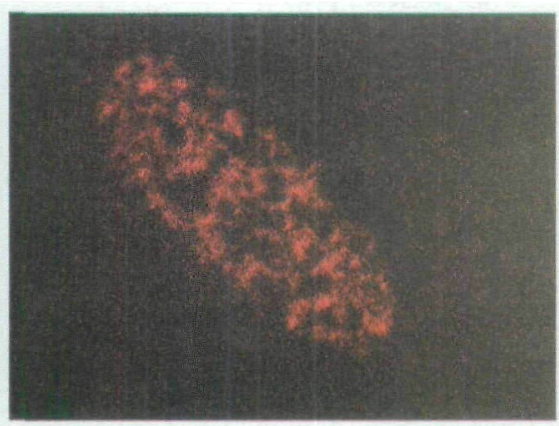

Biotin
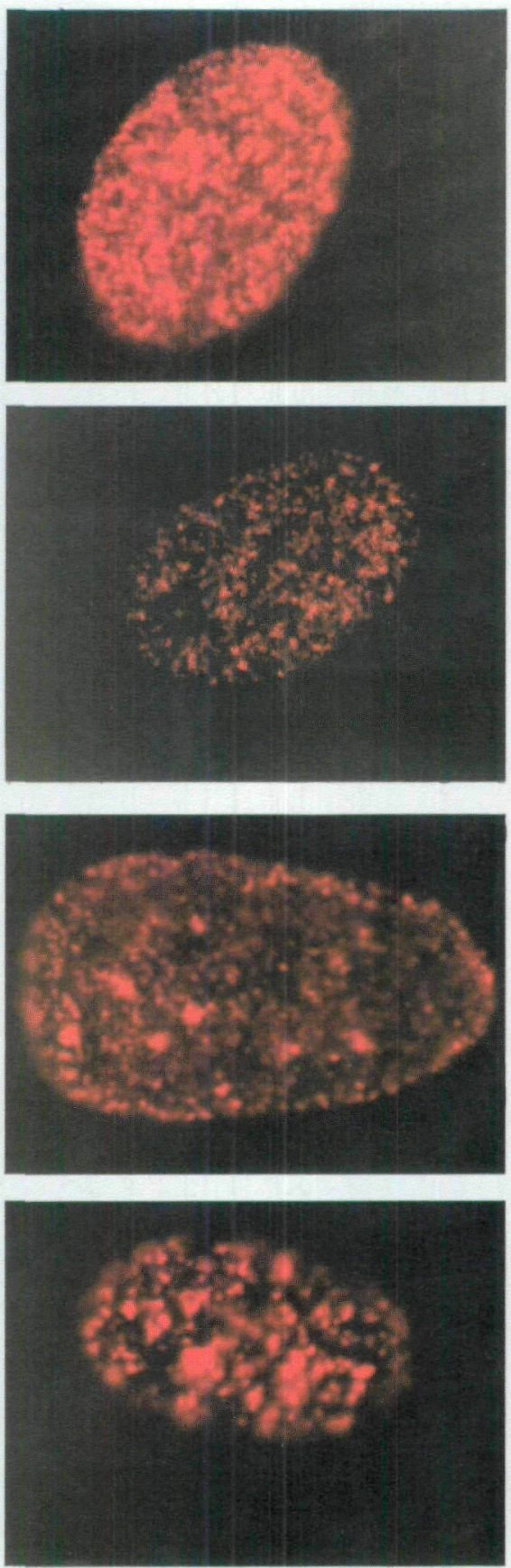

Merged

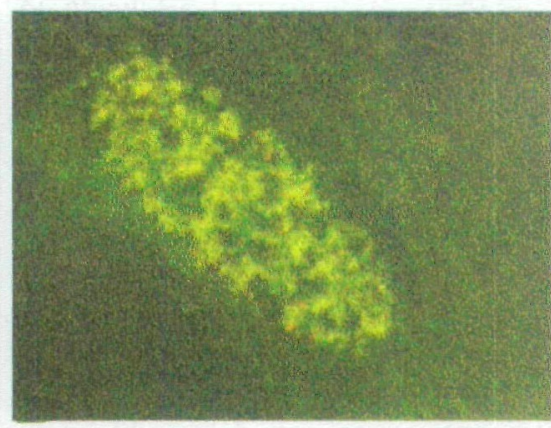

Merged
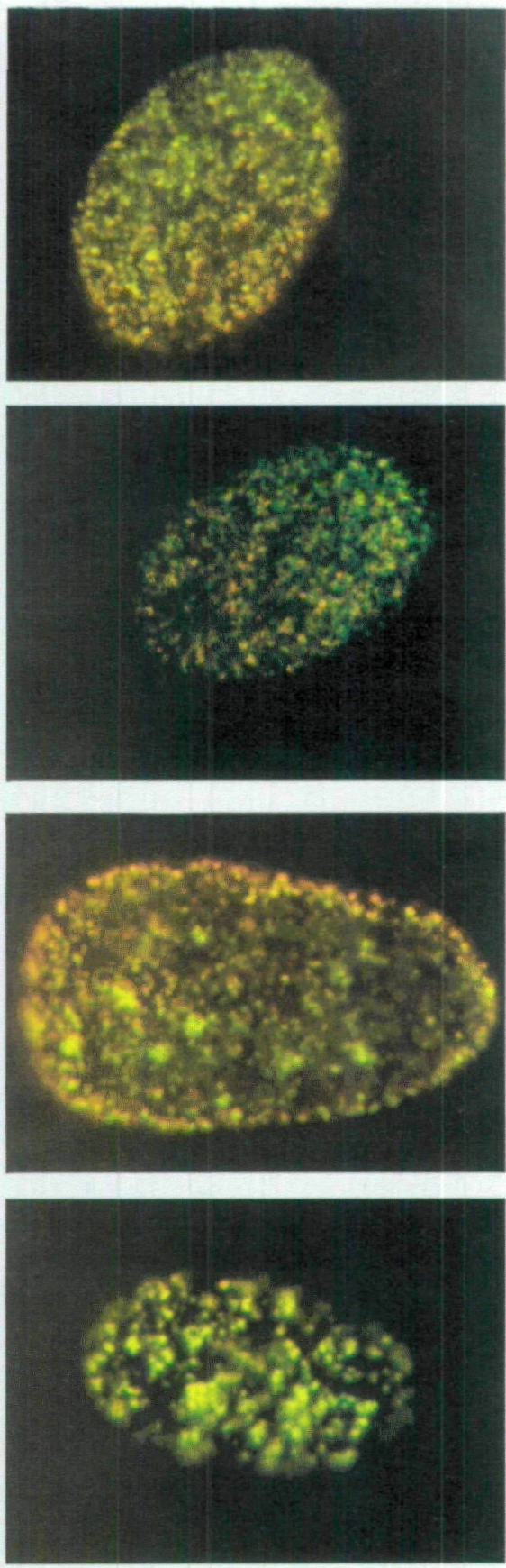


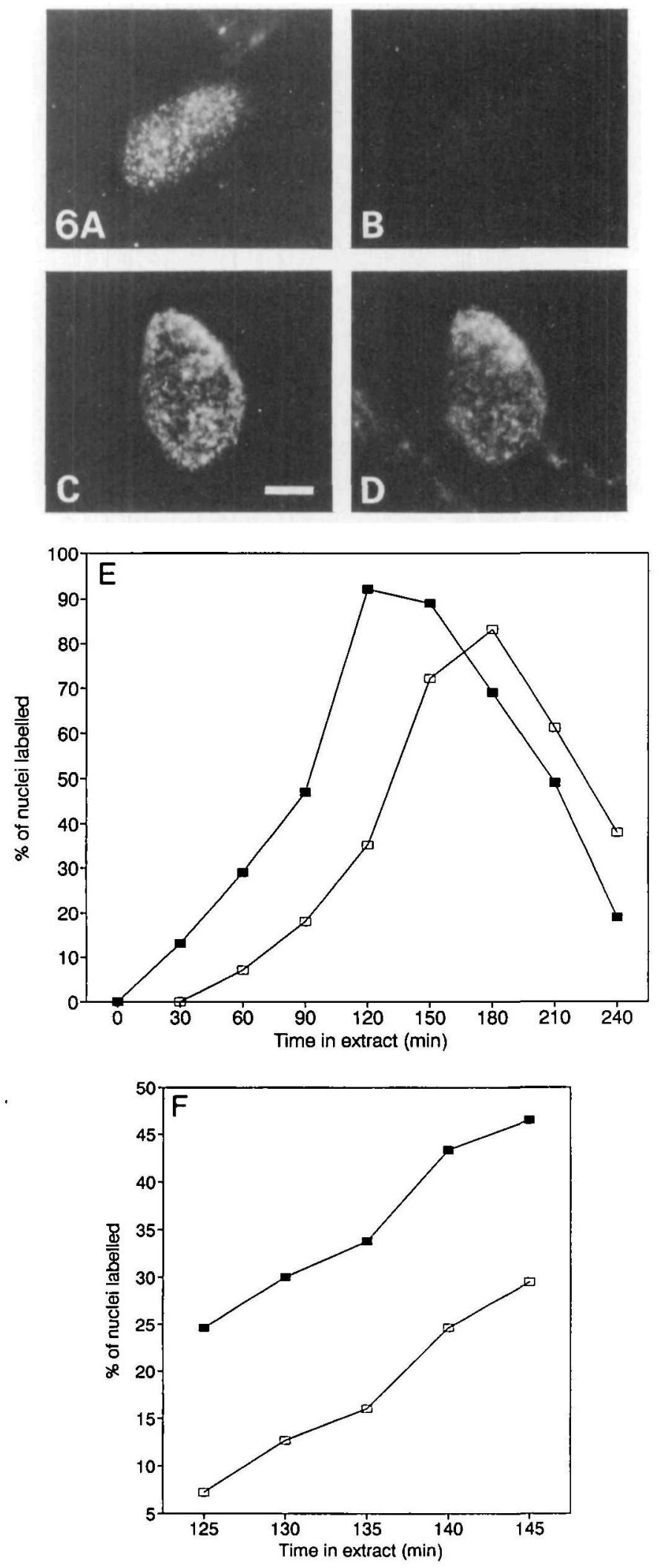

events may occur in nuclei released into egg extracts but would be more difficult to detect.

Our results imply that in order to start synthesising DNA, 'replicase clusters' must be modified in some way. This could occur by a number of different mechanisms such as post-translational modification of one or more
Fig. 6. Indirect immunofluorescence microscopy of isolated nuclei replicating in cell-free extracts of Xenopus eggs. Nuclei were isolated from HDF by homogenisation and incubated in egg extracts. Extracts were pulse labelled with biotin-11-dUTP for $30 \mathrm{~min}$ periods at $30 \mathrm{~min}$ intervals or for $5 \mathrm{~min}$ periods at 5 min intervals. After labelling, nuclei were fixed with EGS and prepared for fluorescence microscopy. Fixed nuclei were stained with Texas red-streptavidin and human anti-PCNA antibodies followed by FITC-rabbit anti-human Ig. Labelled nuclei were observed using a $100 \times$ Neofluor objective fitted to a Zeiss Axioskop. Panel E illustrates the percentage of PCNA and biotin-positive nuclei at each time point following a thirty minute pulse label. Panel F illustrates the percentage of PCNA (更) and biotin-positive ( $\square$ ) nuclei following a five minute pulse label. Values were obtained from scores of 200 nuclei per time point. Panels A and B are micrographs of a nucleus showing reactivity with anti-PCNA antibodies but not streptavidin. Panels $\mathrm{C}$ and $\mathrm{D}$ are micrographs of a nucleus showing reactivity with both anti-PCNA antibodies and extravidin. Scale bar, $5 \mu \mathrm{m}$.

components of the complex by a protein kinase or phosphatase, addition of a single component to the complex or removal of an inhibitory element from the complex. Whatever this mechanism involves, our results do not give any clues as to signalling devices that are used in order to determine when initiation occurs. Other studies have revealed that nuclei act as independent and integrated units of replication in egg extracts (Blow and Watson, 1987). The implication of this is that each nucleus is able to 'sense' its competence to complete one round of replication within a common cytoplasmic environment that induces entry into S-phase. Thus, entry into S-phase may be biphasic, signals in the cytoplasm first allowing the assembly of replicase clusters, this being followed by a second signal within the nucleus which allows those complexes to be used.

The temporal sequence of patterns of DNA replication differs in culture and egg extracts

In common with other studies, we have observed three different patterns of DNA replication and PCNA distribution in fibroblasts grown in culture (Nakamura et al. 1986; Bravo and MacDonald-Bravo, 1987; Nakayasu and Berezney, 1989; Fox et al. 1991). These patterns appear to reflect a temporal sequence of replication in which euchromatin and nucleolar DNA is replicated before heterochromatin (Bravo and MacDonald-Bravo, 1987; Nakayasu and Berezney, 1989). The precise sequence is disputed; studies in vitro indicate that perinuclear synthesis occurs before internal heterochromatic regions are synthesised (Nakayasu and Berezney, 1989). However, more recent studies, in which a cooled coupled device was used to compare DNA content to the distribution of replicons in cultured $3 \mathrm{~T} 3$ cells, indicated that perinuclear heterochromatin replicates last (Fox et al. 1991). Our results support the data of Nakayasu and Berezney (1989) and we feel that the sequence of non-coincident staining patterns is compelling evidence that perinuclear heterochromatin replicates prior to internal heterochromatic regions. The discrepancy between our data and that of Fox et al. (1991) may arise from the way in which these authors collected their data. In order to reveal the sites of DNA synthesis by detecting BrdUrd incorporation, cells were pre-treated with nucleases (Fox et al. 1991). If cells at different stages of S-phase are unequally sensitive to nuclease digestion this may give rise to inaccuracies in the measurement of relative DNA content.

Replicase clusters in S-phase fibroblast nuclei 
Nuclei released into egg extracts display only a single pattern of DNA replication, resembling those observed in sperm pronuclei (Mills et al. 1989). Following inoculation into egg cytoplasm, somatic nuclei undergo extensive reorganisation involving decondensation of heterochromatin, loss of nucleoli, expansion of the nuclear envelope and modification to the lamina (Gurdon, 1976; J. M. Bridger and C. J. Hutchison, unpublished data). This reorganisation precedes replication and gives rise to a uniform distribution of chromatin within the nucleus. To complete this reorganisation, the replacement of somatic cell lamins with the embryonic form of Xenopus lamin Liii appears to be critical (C. M. Crompton and C. J. Hutchison, unpublished data). Indeed, nuclei constructed in Xenopus egg extracts that have been depleted of lamin Liii are unable to organise replicase clusters (Meier et al. 1991). Furthermore, a clonal cell line derived from the human adenocarcinoma SW-13, that lacks lamin A and C, only displays a single pattern of PCNA distribution that resembles type $B$ above and persists throughout S-phase (C. J. Hutchison, L. Reed and P. R. Cook, unpublished data). Thus, the temporal sequence of replication patterns may be dependent upon the way in which lamins influence higher order chromatin structure, and as a consequence, restrict accessibility of replication proteins to origins.

The authors wish to express their thanks for the help and encouragement of Prof. David Glover and for allowing us to use his confocal microscope. We are also grateful to Dr Paul Parker and Mrs Judy Fantes of the Western General Hospital, Edinburgh for their advice. Peter Cook of the Dunn School of Pathology, University of Oxford, has and continues to give helpful and stimulating discussions. This work was supported by grants from the MRC and CRC, and by a training grant from SERC to J.M.B.

\section{References}

Arlett, C. F, Harcourt, S. A. and Broughton, B. C (1975) The influence of caffeine on cell survival in excision-proficient and excision-deficient xeroderma pigmentosum and normal human cell strains following ultraviolet-light irradiation. Mutation Res. 33 341-346.

BLow, J. J. ANd Watson, J V. (1987). Nuclel act as independent and integrated units of replication in a Xenopus cell-free DNA replication system. EMBO J. 6, 1997-2002.

Bravo, R. (1986). Synthesis of the nuclear protein cyclin (PCNA) and its relationship with DNA replication. Expl Cell Res. 163, 287-293.

Bravo, R., Franke, R., Blundell, P. A. and MacDonald-Bravo, H. (1987). Cyclin/PCNA is the auxilliary protein of DNA polymerase S. Nature 326, 515-517.

Bravo, R. and Celis, J E. (1978). A search for differential polypeptide synthesis throughout the cell-cycle of HeLa cells. J. Cell Biol. 84, $795-802$.

Bravo, R. and MacDonald-Bravo, H (1987). Existence of two populations of cyclin/PCNA during the cell-cycle. association with DNA replication sites. J. Cell Biol. 105, 1549-1554.

Fairman, M., Prelich, G., Tsurimoto, T. and Stillman, B. (1988) Identification of cellular components required for SV40 DNA replication in vitro. Biochim biophys. Acta 951, 382-387.

Fairman, M. and Stillman, B. (1988). Purification and characterisation of factors required for SV40 DNA replication in vitro. EMBO J.7, 1211-1218

Fox, M. H., Arndt-Jovin, D. J., Jovin, T. M., Baumann, P. H. and ROBERT-NiCOUD, M. (1991). Spatial and temporal distribution of DNA replication sites localized by immunofluorescence and confocal microscopy in mouse fibroblasts. $J$ Cell Scl 99, 247-253.
Graham, C. F. and Morgan, R. W. (1966). Changes in the cell-cycle during early amphibian development. Deul Biol. 14, 439-461.

Gurdon, J. B. (1976). Injected nuclei in frog oocytes. Rate, enlargement and chromatin dispersal. J. Embryol. exp. Morph. 36, 523-540.

Hutchison, C. J., Cox, R. AND Ford, C. C. (1988). The control of DNA replication in a cell-free extract that recapitulates a basic cell-cycle in vitro. Development 103, 553-566.

Hutchison, C. J. AND KILL, I. R. (1989). Changes in the nuclear distribution of DNA polymerase alpha and PCNA/cyclin during the progress of the cell cycle, in a cell-free extract of Xenopus eggs. J. Cell Sct. 93, 605-613.

JACkson, D. A. AND Cook, P. R. (1986). Replication occurs at a nucleoskeleton. EMBO J. 5, 1403-1410.

Jaskulski, D., DeRiel, J. K., Mercer, W. E., Calabretta, B. and BASERGA, R. (1988). Inhibition of cellular proliferation by antisense oligonucleotides to PCNA/cyclin. Science 240, 1544-1546.

Lee, C. K. AND KNIPE, D. M. (1983). The thermolabile in vivo DNAbinding activity associated with a protein encoded by mutants of Herpes simplex virus type 1. J. Virol. 46, 909-919.

Matthews, M. B., Bernstein, R. M., Franza, B. R. and Garreis, J. I. (1984). Identity of the proliferating cell nuclear antigen and cyclin. Nature 309, 374-376.

Meier, J., Campbell, K. H. S., Ford, C. C., Stick, R. and Hutchison, C. J. (1991). The role of lamin Lili in nuclear assembly and DNA replication, in cell-free extracts of Xenopus eggs. J. Cell Sci. 98, 271-279.

Milis, A., Blow, J. J., White, J. G., Amos, W. B., Wilcock, D. AND LASKEY, R. A. (1989). Replication occurs at discrete foci spaced throughout nucles replicating in vitro. J. Cell Sci. 94, 471-477.

MiYachi, K., Fritzler, M. J. and TaN, C-K. (1978). Autoantibody to a nuclear antigen in proliferating cells. J. Immun. 121, 2228-2234

MorRis, G. F. AND MatThews, M. B. (1989). Regulation of proliferating cell nuclear antigen during the cell cycle. J. biol. Chem. 264 13 856-13864.

Nakamura, H., Morita, T. and SATo, C. (1986). Structural organizations of replicon domains during DNA sythetic phase in the mammalian nucleus. Expl Cell Res. 165, 291-297.

NAKayasu, H. AND Berezney, R. (1989). Mapping replicational sites in the eukaryotic cell nucleus. J. Cell Biol. 108, 1-11.

Prelich, G., Kostura, M., Marshak, D. R., Matthews, M. B. and Stillman, B. (1987a). The cell-cycle regulated proliferating cell nuclear antigen is required for SV40 DNA replication in vitro. Nature 326, 471-475.

Prelich, G. AND Stillman, B. (1988). Coordinated leading and lagging strand synthesis during SV40 DNA replication in vitro requires PCNA. Cell 53, 117-126.

Prelich, G., Tan, C-K., Kostura, M., Matthews, M. B., So, A. G. Downey, K. M. AND Stillman, B. (1987b). Functional identity of proliferating cell nuclear antigen and a DNA polymerase delta auxilliary protein. Nature 326, 517-520.

QuinlaAn, M. P. Chen, L. B. AND KNIPE, D. M. (1984). The intranuclear location of a Herpes simplex virus DNA binding protein is determined by the status of viral DNA replication. Cell 36, 857-868.

QuiNLAN, M. P. AND KNIPE, D. M. (1983). Nuclear localization of herpes virus proteins: potential role for the cellular framework. Molec. cell. Biol. 6, 315-324.

Stillman, B. AND Glutzman, Y. (1985). Replication and supercoiling of simian virus 40 DNA in cell extracts from human cells. Molec. cell. Biol. 5, 2051-2060.

Tan, C. K., Castillo, C., So, A. G. and Downey, K. M. (1986) An auxiliary protein for DNA polymerase delta from fetal calf thymus. J. biol. Chem. 261, 12310-12316

WILCOCK, D aND LANE, D. P. (1991). Localization of p53, retinoblastoma and host replication proteins at sites of viral replication in herpesinfected cells. Nature $349,429-431$.

Wong, R. L., Katz, M. E., OGata, K., TaN, E M. and Cohen, S. (1987). Inhibition of nuclear DNA synthesis by an autoantibody to proliferating cell nuclear antigen/cyclin. Cell Immun. 110, 443-448.

ZUBER, M., TAN, E. M. AND RYOJI, M. (1989) Involvement of proliferating cell nuclear antigen (cyclin) in DNA replication in living cells. Molec. cell. Biol. 9, 57-66.

(Received 15 April 1991 - Accepted, in revised form, 20 September 1991) 